Original

\title{
Determination of Acrylamide in Processed Foods by LC/MS Using Column Switching
}

\author{
(Received October 2, 2002) \\ Satoshi Takatsuki ${ }^{\dagger}$, Satoru Nemoto, Kumiko Sasaki and Tamio Maitani \\ (National Institute of Health Sciences: 1-18-1, Kamiyoga, Setagaya-ku, \\ Tokyo 158-8501, Japan; ${ }^{\dagger}$ Corresponding author)
}

\begin{abstract}
An LC/MS method was developed for the determination of acrylamide (AA) in processed or cooked foods. AA was extracted with a mixture of water and acetone from homogenized food samples after the addition of ${ }^{13} \mathrm{C}$-labeled acrylamide $\left(\mathrm{AA}-1-{ }^{13} \mathrm{C}\right.$ ) as an internal standard. The extract was concentrated, washed with dichloromethane for defatting, and cleaned up on Bond Elut C18, PSA and ACCUCAT cartridge-columns, and then AA was determined by LC/MS in the selected ion recording (SIR) mode. For the LC/MS analysis, four LC columns were connected in-line and the flow of the mobile phase was switched according to a time-program. Monitoring ions for AA were $m / z 72$ and 55 , and those for AA- $1-{ }^{13} \mathrm{C}$ were $m / z 73$ and 56 . AA and AA- $1-{ }^{13} \mathrm{C}$ were determined without interference from the matrices in all samples. The recoveries of AA from potato chips, corn snack, pretzel and roasted tea spiked at the level of $500 \mathrm{ng} / \mathrm{g}$ of AA were 99.5$101.0 \%$ with standard deviations (SD) in the range from 0.3 to $1.6 \%$. The limits of detection and quantification of the developed method were 9 and $30 \mathrm{ng} / \mathrm{g}$ for AA in samples, respectively.

The method was applied to the analysis of AA in various processed or cooked food samples purchased from retail markets. High levels of AA were found in potato chips and French-fried potato (467-3,544 ng/g). Fried and sugar-coated dough cakes (karinto) contained 374 and 1,895 ng/g. Corn snacks contained 117-535 ng/g of AA. Roasted foods (such as roasted sesame seed, roasted barley (mugi-cha), roasted tea (hoji-cha), coffee beans and curry powder) contained 116$567 \mathrm{ng} / \mathrm{g}$ of AA. Foods made from fish, egg and meat contained lower levels of AA than the plant-based foods. Foods containing much water showed a tendency to have low levels of AA compared with dry foods.

The proposed method was applicable to the analysis of AA in variety of processed foods.
\end{abstract}

Key words: acrylamide; ${ }^{13} \mathrm{C}$-labeled acrylamide; LC/MS; column switching; potato chips; French-fried potato; roasted tea

\section{Introduction}

In April 2002 the Swedish National Food Administration and researchers from the Stockholm University announced their findings that acrylamide (AA), a neurotoxic and probably carcinogenic chemical in humans, was present in many types of foods (especially potato chips, French-fried potato, biscuits, and cereals) prepared or cooked at high temperature*1. Thereafter, the details of the findings were reported ${ }^{1), 2)}$. AA is a chemical used for the synthesis of polyacrylamide or other chemical products, and it had not been found in normal foods. Confirmation of the finding was reported from Norway, Switzerland, the United Kingdom and the United States in the "Joint FAO/WHO Expert Consultation on Health Implications of Acrylamide in Foods" held in June $2002 * 2$.

The effect of AA in foods on human health has been

*1 http://www.slv.se/engdefault.asp

*2 http://www.li.se/dokument/news / nyheter / Acrylamid\% 20Expertrapport\%20Final.pdf unknown and maximum levels for AA in foods have not been established. It is necessary to develop analytical methods of AA in foods and to determine AA in various foods for prospective risk assessment. Most of the analytical methods reported for analysis of AA in foods are based on derivatization followed by $\mathrm{GC}-\mathrm{ECD}^{3)}$, $\mathrm{GC} / \mathrm{MS}^{4-6)}$ or $\mathrm{LC} / \mathrm{MS}^{7}$. We have reported an analytical method of AA in foods using $\mathrm{GC} / \mathrm{MS}$ after bromination of $\mathrm{AA}^{8)}$. In recent reports, low levels of $\mathrm{AA}$ were determined by LC/MS/MS ${ }^{1,2)}$, but an LC/MS method without derivatization has not been fully reported*3.

In the present study we devised an LC/MS system equipped with four columns, three pumps and two valves for column switching to determine AA in foods. The proposed method was applied to the analysis of AA in various processed or cooked foods including characteristic Japanese foods purchased from the retail markets.

\footnotetext{
*3 The 51st Meeting of The Japan Society for Analytical Chemistry, Abstract, p. 157 (19-21 September, 2002)
} 


\section{Materials and Methods}

\section{Samples}

Food samples for the recovery test and the examination of AA content were purchased from retail markets in Tokyo from May to September 2002. Those samples (after homogenization for solid samples) were stored at $-30^{\circ} \mathrm{C}$ until analysis. Some cooked samples were analyzed immediately after cooking (such as French-fried potato, omelets, deep-fried fish and deep-fried meat). Tempura batter coatings were analyzed. Bread-crumb coating of deep-fried fish and croquette were analyzed, as were both whole and bread-crumb coating of fried cake of minced meats and deep-fried horse mackerel. Some samples tested were the same as those analyzed by $\mathrm{GC} / \mathrm{MS}$ in the preceding paper ${ }^{8}$.

\section{Reagents}

Standards: acrylamide, for electrophoresis (Kanto Chemical Co., Inc., Tokyo, Japan), purity 99.9\%; internal standard, acrylamide- $1-{ }^{13} \mathrm{C}$ (AA- $\left.-1{ }^{13} \mathrm{C}\right)$ (CDN Isotopes Co., Quebec, Canada), 99 atom $\%{ }^{13} \mathrm{C}$.

Stock standard solutions $(100 \mu \mathrm{g} / \mathrm{mL}): 10 \mathrm{mg}$ each of $\mathrm{AA}$ or $\mathrm{AA}-1-{ }^{13} \mathrm{C}$ was exactly measured in $100-\mathrm{mL}$ brown glass volumetric flasks and made up to $100 \mathrm{~mL}$ with water. The stock solutions were stored at $4{ }^{\circ} \mathrm{C}$.

Calibration standard solutions: Aliquots of AA standard solutions (equivalent to 0, 50, 100, 500, 1,000, 2,000 and 5,000 ng of AA) were mixed with $20 \mu \mathrm{L}$ of internal standard solution (100 $\mu \mathrm{g} / \mathrm{mL}$ AA-1-13C) and made up to $10 \mathrm{~mL}$ with water.
Cartridge columns: Bond Elut C18 (500 mg/3 mL), Bond Elut Jr-PSA (500 mg) and Bond Elut ACCUCAT $(600 \mathrm{mg} / 3 \mathrm{~mL})$ were from Varian, Inc., CA, USA. Bond Elut $\mathrm{C} 18$ was conditioned with $2 \mathrm{~mL}$ of methanol and successively with $4 \mathrm{~mL}$ of water before use. The other columns were conditioned only with $4 \mathrm{~mL}$ of water before use.

Acetone: high quality for pesticide residue analysis (Kanto Chemical Co., Inc.).

Dichloromethane, methanol and water: HPLC grade (Kanto Chemical Co., Inc.).

\section{Apparatus}

A liquid chromatograph/mass spectrometer equipped with a column switching system was used. The construction of the apparatus is shown in Fig. 1. Four columns were used. Switching valves were inserted between column-1 and -2 , and column -2 and -3 .

Liquid chromatograph/mass spectrometer: model 2690 separation module liquid chromatograph (Waters, Co., Milford, MA, USA) coupled with a model Platform LCZ mass selective detector (Micromass UK Ltd., Altrincham, UK).

Degasser: ERC-3215 $\alpha$ (ERC Inc., Kawaguchi, Japan)

Switching valve: LabPRO (Rheodyne, Cotati, CA, USA) and EV700-100 (GL Sciences, Tokyo, Japan)

Pump: LC-10AD and LC-10ADvp (Shimadzu Co., Kyoto, Japan)

Homogenizer: Polytron (KINEMATICA AG, Littau, Switzerland)

Concentrator: Turbo Vap 500 (Zymark Co., Hopkin-

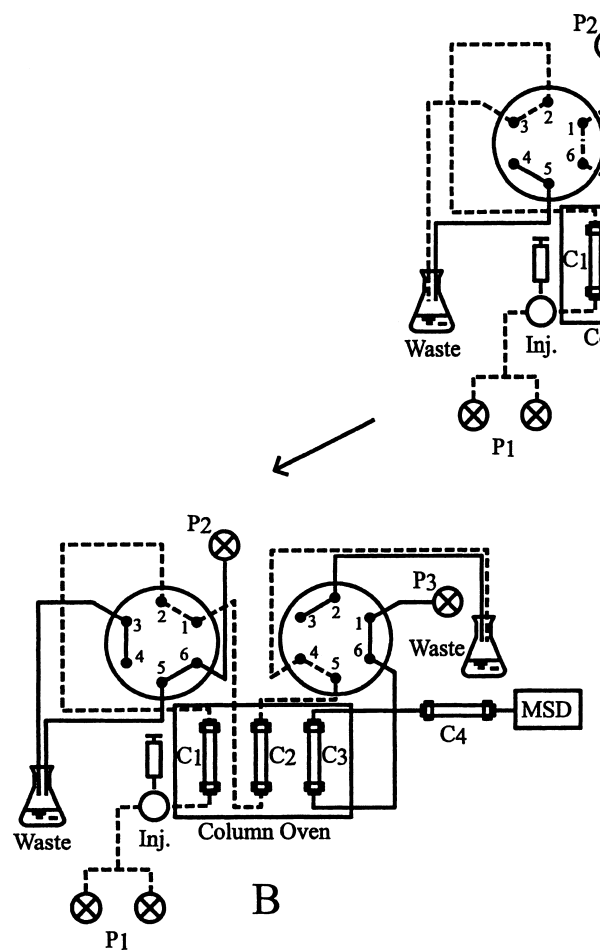

Fig. 1. Construction of the LC/MS system

Inj: injector; P1, P2, P3: pumps; C1, C2, C3, C4: columns; MSD: mass spectrometer

The pathway of mobile phase was (A) during the analysis except in the periods from 1.75 to 2.05 min (B) and from 4.66 to $5.15 \mathrm{~min}(\mathrm{C})$. 
ton, MA, USA)

\section{LC/MS conditions}

Column: column-1, Hypercarb $(50 \times 2.1 \mathrm{~mm}$ i.d., particle size $5 \mu \mathrm{m}$, Thermo Hypersil-Keystone, Runcorn, UK); column-2, Shodex MSpak GF-310 4B (50×4.6 mm i.d., particle size $6 \mu \mathrm{m}$, Shoko. Co. Ltd., Tokyo, Japan); column-3, Atlantis dC18 $(150 \times 2.1 \mathrm{~mm}$ i.d., particle size 5 $\mu \mathrm{m}$, Waters Co., Milford, MA, USA); column-4, Develosil RPAQUEOUS-AR-3 $(35 \times 2.0 \mathrm{~mm}$ i.d., particle size $3 \mu \mathrm{m}$, Nomura Chemical Co., Ltd., Seto, Japan)

Column oven temp.: $40^{\circ} \mathrm{C}$ for the column-1, -2 and -3 , and room temperature for the column- 4

Mobile phase composition: $0.1 \%$ acetic acid-methanol $(95: 5)$

Flow rate; $0.25 \mathrm{~mL} / \mathrm{min}$

Sampling time from column-1 to column-2: 1.75-2.05 $\min$

Sampling time from column-2 to column-3: 4.66-5.15 $\min$

AA elution time from column-4: $8.5 \mathrm{~min}$

Source block temp.: $120^{\circ} \mathrm{C}$

Desolvation temp.: $350^{\circ} \mathrm{C}$

Gas: nitrogen, flow rate, ca.300 L/hr

Capillary voltage: $3.50 \mathrm{eV}$

Ionization mode: positive ion electron spray

Measuring mode: selected ion recording (SIR)

Monitoring ion and corn voltage: $m / z 72$ (AA) and $m / z 73\left(\mathrm{AA}-1-{ }^{13} \mathrm{C}\right)$ at $24 \mathrm{~V}$ of corn voltage and $m / z 55$ (AA) and $m / z 56\left(\mathrm{AA}-1{ }^{13} \mathrm{C}\right)$ at $40 \mathrm{~V}$ of corn voltage

Injection volume: $10 \mu \mathrm{L}$

\section{Sample preparation}

A sample $(5.0 \mathrm{~g})$ was weighed into a $250-\mathrm{mL}$ glass tube and $20-25 \mathrm{~mL}$ of water and $100 \mu \mathrm{L}$ of internal standard solution ( $100 \mu \mathrm{g} / \mathrm{mL}$ AA $-1-{ }^{13} \mathrm{C}$ solution) were added to the sample. The mixture was allowed to stand for $30 \mathrm{~min}$ with occasional shaking. Acetone $(50 \mathrm{~mL})$ was added and the mixture was homogenized for $1 \mathrm{~min}$ with a homogenizer. The homogenate was filtered through a glass filter (GA-100), and the residue on the filter was washed with $30 \mathrm{~mL}$ of acetone. The filtrate was concentrated to less than $15 \mathrm{~mL}$ with a concentrator at $35^{\circ} \mathrm{C}$. The concentrate was transferred to a $50-\mathrm{mL}$ centrifugal tube, washed twice with $20 \mathrm{~mL}$ each of dichloromethane by shaking for $1 \mathrm{~min}$ and centrifuged at 2,700 rpm for $5 \mathrm{~min}$. The water layer was made up to $15 \mathrm{~mL}$ with water.

An aliquot of the extract ( $3 \mathrm{~mL}$, equivalent to $1.0 \mathrm{~g}$ of sample) was passed through a C18 cartridge column, followed by washing with $2 \mathrm{~mL}$ of water. All the eluate was collected and made up to $5 \mathrm{~mL}$ with water. An aliquot of the eluate $(2 \mathrm{~mL}$, equivalent to $0.4 \mathrm{~g}$ of sample) was passed through an ACCUCAT column connected to a PSA column, followed by washing with 2 $\mathrm{mL}$ of water. All the eluate was collected and made up to $4 \mathrm{~mL}$ with water to prepare the test solution.

\section{Determination and confirmation of $A A$}

AA was determined by LC/MS (SIR). The quantification was performed by comparison of the peak area ratios of $m / z 72(\mathrm{AA})$ and $m / z 73\left(\mathrm{AA}-1{ }^{13} \mathrm{C}\right.$ ) for the test solution with those for the calibration standard. The peak area ratio of $m / z 55$ (AA) and $m / z 56$ (AA- $1-{ }^{13} \mathrm{C}$ ) was used for confirmation. The recovery of internal standard was calculated from the peak areas of AA$1-{ }^{13} \mathrm{C}$ in the test solution and the calibration standard.

The calibration standard ( $\mathrm{AA}=0, \mathrm{AA}-1-{ }^{13} \mathrm{C}=200 \mathrm{ng}$ / $\mathrm{mL}$ ) contained a small quantity of $\mathrm{AA}$ as an impurity of AA- $1-{ }^{13} \mathrm{C}$. Therefore, the limit of detection (LOD) was defined as 3 times the SD of the AA peak area of the calibration standard (AA $=0, A A-1-{ }^{13} \mathrm{C}=200 \mathrm{ng} / \mathrm{mL}$ ). The limit of quantification (LOQ) was defined as 10 times the SD.

\section{Results and Discussion}

\section{LC/MS conditions}

In MS analysis, AA gave only a few small ions at any corn voltage. Ions $m / z 72(\mathrm{M}+\mathrm{H})$ at corn voltage $24 \mathrm{~V}$ and $m / z 55\left(\mathrm{M}-\mathrm{NH}_{2}\right)$ at corn voltage $40 \mathrm{~V}$ were chosen for quantification and confirmation, respectively.

Some test solutions prepared by the proposed method still contained matrices interfering with the analysis of $\mathrm{AA}$ and $\mathrm{AA}-1-{ }^{13} \mathrm{C}$, and it was difficult to separate AA from interfering components completely by using one or two LC columns. Consequently, four LC columns having different properties were used with 2 switchings to obtain the best separation of AA. The fourth column was used to narrow the peak width of AA. Two switchings might be reduced to one by using other LC columns or longer ones.

Under these conditions, the analytical values obtained by using the ion $\mathrm{m} / z 72$ were well correlated with the values obtained by using the ion $\mathrm{m} / z 55$ in all samples. When the test solutions of roasted coffee bean, roasted tea, cocoa and meat products were monitored at $m / z 55$, some peaks were observed near the AA peak, but these peaks did not interfere with the analysis of AA.

The SIR chromatograms of the extracts of potato chips and roasted coffee bean are shown in Fig 2. The SIR chromatograms of the other foods were similar to
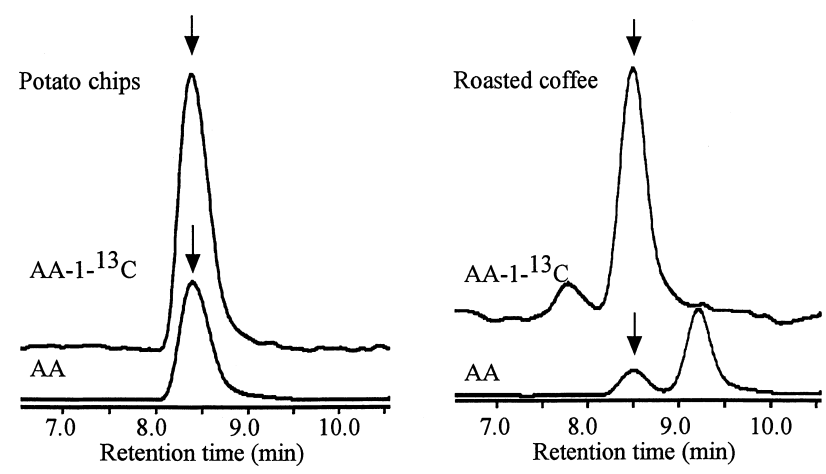

Fig. 2. SIR chromatograms of acrylamide (AA, $m / z 72$ ) and internal standard $\left(\mathrm{AA}-1-{ }^{13} \mathrm{C}, \mathrm{m} / z\right.$ 73) in food samples 
those of potato chips.

\section{Extraction}

AA is very soluble in water $\left(2,155 \mathrm{~g} / \mathrm{L}, 30^{\circ} \mathrm{C}\right)$, so in most cases AA is well extracted with water ${ }^{1)-8)}$ from samples. AA dissolved in water was hard to trap on any absorbent and the aqueous solution could not be concentrated without loss of AA. On the other hand, a sufficient amount of water should be used to extract AA entirely from samples, and it resulted in the dilution of $\mathrm{AA}$ in the test solution. Therefore, a mixture of water and acetone was used for the extraction, and acetone in the extract was removed by concentration before the clean-up procedure. Although acetone extraction without water gave good recovery of AA from spiked potato chips and the extract was clean compared with the water extract, acetone without water failed to extract AA contained originally in the sample.

\section{Clean-up procedure}

Some matrices in the food samples affected the ionization of AA in MS analysis even though they did not show interfering peaks with detection in SIR. Therefore, it was necessary to clean up the extract sufficiently for accurate analysis. The sample extract was defatted by washing with dichloromethane. Additional clean-up was examined using several cartridge columns, C18, PSA, ACCUCAT, Envi Carb (1,000 mg, Supelco), Oasis HLB (60 mg and $200 \mathrm{mg}$, Waters), and ISOLUTE Multi Mode (500 mg, International Sorbent Technology). No solid-phase trapped AA, so the columns were used to trap water-soluble matrices and to pass AA. The most suitable columns examined were C18, PSA and ACCUCAT. The solid-phase materials of $\mathrm{C} 18$ and ACCUCAT were the same as that of Multi Mode used in the LC/MS/MS method ${ }^{1)}$. The sample extract was passed through these columns, followed by washing with water. The proposed clean-up procedure was sufficient to analyze AA in the potato products, but further clean-up was necessary for the other foods. No other suitable column was found, and ultrafiltration using a spin filter with $3 \mathrm{kDa}$ cut off was not effective to remove the interference, so the LC/MS with a column switching system was applied.

\section{Calibration curve and detection limit}

The calibration curve was prepared using AA- $1-{ }^{13} \mathrm{C}$ as an internal standard. The calibration curve was linear in the range of 5 to $500 \mathrm{ng} / \mathrm{mL}$ of AA with a correlation coefficient $r^{2}$ of 0.999 .

The purity of AA- $1-{ }^{13} \mathrm{C}$ used was 99 atom $\%{ }^{13} \mathrm{C}$, so the calibration standard $\left(\mathrm{AA}=0, \mathrm{AA}-1-{ }^{13} \mathrm{C}=200 \mathrm{ng} / \mathrm{mL}\right)$ showed a response at $m / z 72$ derived from AA as an impurity of $\mathrm{AA}-1-{ }^{13} \mathrm{C}$. It corresponded to about $1 \%$ of the response at $m / z 73$ of $\mathrm{AA}-1-{ }^{13} \mathrm{C}$. The LOD was defined as 3 times the $\mathrm{SD}$ of the $\mathrm{AA}$ peak area of a calibration standard $\left(\mathrm{AA}=0, \mathrm{AA}-1-{ }^{13} \mathrm{C}=200 \mathrm{ng} / \mathrm{mL}\right)$. The LOQ was defined as 10 times the SD. The LOD on a sample mass basis was $9 \mathrm{ng} / \mathrm{g}$ and the LOQ was 30 $\mathrm{ng} / \mathrm{g}$. The LOD was similar to the LOD (10 ng/g) reported for the LC/MS/MS method ${ }^{1,2)}$ and to the values reported in our preceding paper by $\mathrm{GC} / \mathrm{MS}^{8}$. Found values between the LOD and LOQ are indicated as trace (tr) in Table 2.

\section{Recovery test and precision of analysis}

The results of the recovery test are shown in Table 1. AA was added to potato chips, corn snack, pretzel and roasted tea leaves at the level of $500 \mathrm{ng} / \mathrm{g}$. These samples were analyzed by the proposed method after the addition of an internal standard at the level of 2,000 $\mathrm{ng} / \mathrm{g}$. The recovery of the internal standard AA- $1-{ }^{13} \mathrm{C}$ was $67.9-82.8 \%$. The control samples contained 50$1,008 \mathrm{ng} / \mathrm{g}$ of AA and the SD values of the found values were $0.4-13 \mathrm{ng} / \mathrm{g}$ (RSD: $0.16-2.4 \%$ ). The mean value and SD of the corrected recoveries for these foods were 99.5-101.0\% and $0.3-1.6 \%$, respectively. The recovery and repeatability were acceptable, which suggests that the proposed method would have a good performance for the analysis of AA in foods.

\section{AA contents in various processed foods}

The analytical results of various commercial food samples are given in Table 2. The recoveries of AA-1${ }^{13} \mathrm{C}$ were calculated to confirm the propriety of each analysis, and were $43.8-86.3 \%$ (68.6 $16.1 \%)$ for all samples. In some samples, the recoveries of internal standard might be reduced by decomposition during the analysis and/or inhibition of the ionization in MS analysis. AA in the standard solution was stable in the dark

Table 1. Recovery of Acrylamide from Spiked Foods

\begin{tabular}{|c|c|c|c|c|c|}
\hline Sample & $\begin{array}{c}\text { Main raw } \\
\text { material }\end{array}$ & $n$ & $\begin{array}{l}\text { Added } \\
(\mathrm{ng} / \mathrm{g})\end{array}$ & $\begin{array}{c}\text { Found } \\
(\mathrm{ng} / \mathrm{g}, \text { mean } \pm \mathrm{SD})\end{array}$ & $\begin{array}{c}\text { Recovery } \\
(\%, \text { mean } \pm \mathrm{SD})\end{array}$ \\
\hline Potato chips & Potato & 3 & $\begin{array}{r}0 \\
500\end{array}$ & $\begin{array}{l}1,008 \pm 1.6 \\
1,507 \pm 1.3\end{array}$ & $99.8 \pm 0.3$ \\
\hline Corn snack & Corn & 3 & $\begin{array}{r}0 \\
500\end{array}$ & $\begin{array}{c}535 \pm 13 \\
1,033 \pm 3.2\end{array}$ & $99.5 \pm 0.6$ \\
\hline Pretzel & Wheat & 3 & $\begin{array}{r}0 \\
500\end{array}$ & $\begin{array}{r}50 \pm 0.4 \\
549 \pm 8.0\end{array}$ & $99.9 \pm 1.6$ \\
\hline $\begin{array}{r}\text { Roasted tea } \\
\text { (Hoji-cha) }\end{array}$ & Tea & 3 & $\begin{array}{r}0 \\
500\end{array}$ & $\begin{array}{r}567 \pm 3.5 \\
1,072 \pm 6.5\end{array}$ & $101.0 \pm 1.3$ \\
\hline
\end{tabular}


Table 2. Analytical Results of Acrylamide in Foods

\begin{tabular}{|c|c|c|c|c|c|c|}
\hline \multirow{2}{*}{$\begin{array}{c}\text { Foods } \\
\text { Storable foods }\end{array}$} & \multirow[t]{2}{*}{ Main raw material } & \multicolumn{5}{|c|}{ Found values (ng/g) } \\
\hline & & & & & & \\
\hline Potato chips & Potato & $\begin{array}{r}3,544^{*} \\
875^{*}\end{array}$ & $\begin{array}{l}2,175 \\
467^{*}\end{array}$ & $1,542^{*}$ & $1,385^{*}$ & $\underline{1,008}$ \\
\hline Potato snacks & Potato & $57^{*}$ & $35^{*}$ & & & \\
\hline Dried mashed potato & Potato & $\mathrm{nd}^{*}$ & & & & \\
\hline Bolo (small round cookie) & Potato & $\operatorname{tr}^{*}$ & & & & \\
\hline Sweet potato snack & Sweet potato & 112 & & & & \\
\hline Deep-fried sweet potato (Imo-kenpi) & Sweet potato & 336 & & & & \\
\hline Corn snack & Corn & $\underline{535}$ & $387^{*}$ & $238^{*}$ & $117^{*}$ & \\
\hline Cereals & Corn & $\overline{122}$ & 113 & & & \\
\hline Pretzel & Wheat & $56^{*}$ & 50 & $48^{*}$ & & \\
\hline Biscuit, Cookie & Wheat & 302 & $2 \overline{47}$ & 124 & & \\
\hline Cracker & Wheat & 302 & 227 & 53 & & \\
\hline Fried and sugar-coated dough cake (karinto) & Wheat & 1,895 & $374^{*}$ & 84 & & \\
\hline Doughnut & Wheat & tr* & & & & \\
\hline Sponge cake (castilla), Cake (baum kuchen) & Wheat & nd & nd & & & \\
\hline Rosted barley flour (mugi-kogashi) & Barley & 236 & & & & \\
\hline Rice cracker (senbei) & Rice & tr* & & & & \\
\hline Deep-fried rice cake (agemochi) & Glutinous rice & 36 & tr* & & & \\
\hline Beans snacks & Immature pea & 101 & & & & \\
\hline Beans snacks & Wheat, soybean & 83 & & & & \\
\hline Roasted and ground bean (kinako) & Soybean & 118 & $31^{*}$ & & & \\
\hline Roasted sesame seed & Sesame & $197^{*}$ & 160 & 136 & 116 & \\
\hline Roasted peanuts & Peanuts & 92 & 57 & & & \\
\hline Fried horsebeans & Horsebeans & 120 & & & & \\
\hline Roasted almonds & Almonds & 324 & & & & \\
\hline Roasted pistachio & Pistachio & 34 & & & & \\
\hline Roasted cashewnut & Cashewnut & $\operatorname{tr}$ & & & & \\
\hline Roasted walnut & Walnut & nd & & & & \\
\hline Apple chips & Apple & nd & & & & \\
\hline Banana chips & Banana & 65 & & & & \\
\hline Vegetable chips (string beans) & String beans & 45 & & & & \\
\hline Vegetable chips (pumpkin) & Pumpkin & 55 & & & & \\
\hline Vegetable chips (carrot) & Carrot & $\operatorname{tr}$ & & & & \\
\hline Vegetable chips (potato) & Potato & $\operatorname{tr}$ & & & & \\
\hline Bread-crumbs & Wheat & 35 & $\operatorname{tr}$ & & & \\
\hline Precooked noodles (Instant noodles) & Wheat & $163^{*}$ & 70 & 57 & tr* & $\operatorname{tr}$ \\
\hline Curry roux & Spice & 116 & & & & \\
\hline Curry powder & Spice & 423 & & & & \\
\hline Green tea & Tea & $\operatorname{tr}$ & nd & & & \\
\hline Roasted tea (hoji-cha) & Tea & 567 & $538^{*}$ & 519 & & \\
\hline Tea & Tea & $\operatorname{tr}$ & nd & & & \\
\hline Oolong tea & Tea & 142 & 97 & $\operatorname{tr}$ & nd & \\
\hline Pu'er tea & Tea & nd & & & & \\
\hline Roasted barley (mugi-cha) & Barley & 270 & $256^{*}$ & & & \\
\hline Roasted coffee bean & Coffee bean & 231 & 153 & $151^{*}$ & & \\
\hline Cocoa powder & Cacao beans & 141 & 104 & & & \\
\hline Skim milk & Milk & $\operatorname{tr}$ & & & & \\
\hline \multicolumn{7}{|l|}{ Perishable foods } \\
\hline French fries & Potato & 784 & 693 & 565 & 512 & \\
\hline Sweet potato snacks (Daigaku-imo) & Sweet potato & 34 & & & & \\
\hline Bread & Wheat & $\operatorname{tr}$ & $\operatorname{tr} *$ & nd & & \\
\hline Boiled buckwheat noodles (soba) & Buckwheat & nd & & & & \\
\hline Boiled Japanese noodles (udon) & Wheat & nd & & & & \\
\hline Cooked rice & Rice & nd & & & & \\
\hline Soybean curd & Soybean & nd & & & & \\
\hline $\begin{array}{l}\text { Toasted or fried soybean curd (yaki-tofu, } \\
\text { ganmodoki, abura-age) }\end{array}$ & Soybean & nd & nd & nd & & \\
\hline Omelet (dashimaki-tamago) & Egg & $\operatorname{tr}$ & & & & \\
\hline Omelet & Egg & nd & & & & \\
\hline Egg roll (harumaki) & Wheat & $\operatorname{tr}$ & & & & \\
\hline
\end{tabular}


Table 2. (Continued)

\begin{tabular}{|c|c|c|c|c|}
\hline Foods & Main raw material & & Found values (ng/g) & \\
\hline \multicolumn{5}{|l|}{ Perishable foods } \\
\hline Egg roll shell & Wheat & 30 & & \\
\hline Fried cake of minced meat & Wheat, meat & $\operatorname{tr}$ & nd & \\
\hline Deep-fried chicken & Chicken, wheat & 36 & $\operatorname{tr}$ & \\
\hline Baked mackerel (saba-shioyaki) & Mackerel & nd & & \\
\hline Batter coating (tempura) & Wheat & $\operatorname{tr} *$ & nd* & \\
\hline Bread-crumb coating & Wheat & $53^{*}$ & 32 & nd \\
\hline Deep-fried horse mackerels & Horse mackerel, wheat & nd & & \\
\hline Tube-shaped fish paste cake (chikuwa) & Fish & nd & nd & \\
\hline Fried fish paste (satsuma-age) & Fish & nd & nd & \\
\hline
\end{tabular}

*: The sample was the same as the one analyzed by GC/MS and reported in the preceding paper8).

Figures underlined were the same as control values in the recovery test (shown in Table 1).

Each figure printed in boldface and italics was the same product produced on different days.

nd: not detected $(<9 \mathrm{ng} / \mathrm{g})$

tr: trace $(9 \leqq \operatorname{tr}<30 \mathrm{ng} / \mathrm{g})$

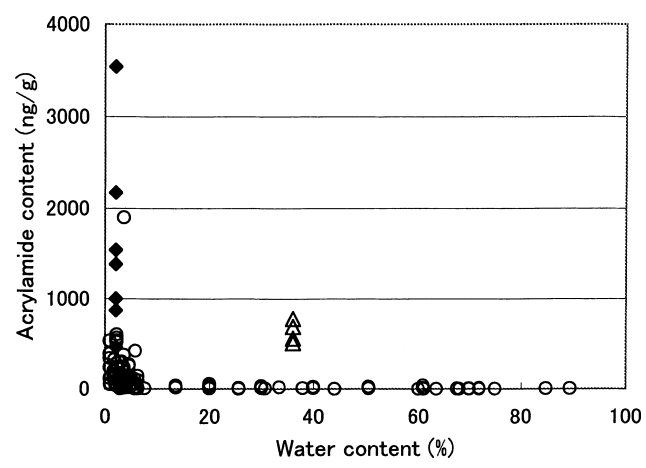

Fig. 3. Correlation between acrylamide and water contents in foods examined

$\checkmark$ : potato chips; $\triangle$ : French-fried potato; $\bigcirc$ : other foods

The water content was taken from "Standard Tables of Food Composition in Japan, fourth (1982) and fifth (2000) revised edition”. For some foods, the values for similar foods were used.

at 4 or $10^{\circ} \mathrm{C}$, but $\mathrm{AA}$ in some test solutions decreased by $20-30 \%$ in one day. The samples marked $\left(^{*}\right)$ were the same as those analyzed by the GC/MS method in the preceding paper ${ }^{8)}$. The values obtained by the LC/MS method correlated well with those obtained by the GC/ MS method, and they were slightly larger (about 6.5\%) than those obtained by GC/MS $\left(y=0.934 x+2.998, r^{2}\right.$ : 0.999). The analyses by the LC/MS method were performed one month after the analyses by GC/MS, so AA must be stable in these foods during this period.

High levels (exceeding 1,000 ng/g) of AA were found in potato chips, as also reported by Swedish researchers $^{* 1}$. The levels of AA in potato chips were 467-3,544 $\mathrm{ng} / \mathrm{g}$. French-fried potato obtained from different fastfood shops contained almost equal levels of AA (512$784 \mathrm{ng} / \mathrm{g})$. A fried and sugar-coated dough cake (karinto) which was indicated to have been fried twice contained 1,895 ng/g of AA, and other "karinto" contained 374 and $84 \mathrm{ng} / \mathrm{g}$ AA. Corn snacks contained $117-535 \mathrm{ng} / \mathrm{g}$ of AA. Roasted food products contained $116-567 \mathrm{ng} / \mathrm{g}$ of AA (such as roasted sesame seed, roasted tea (hoji-cha), roasted barley (mugi-cha), coffee beans and curry powder). The AA levels in the staple foods were $<$ LOD-70 ng/g (such as cooked rice, boiled noodles (soba and udon), bread and precooked (instant) noodles). An instant noodle sample that contained 163 $\mathrm{ng} / \mathrm{g}$ of AA was a snack-type product, and it was taken without cooking. The foods made from fish, egg and meat contained lower levels of AA than the plant-based foods.

The products made by the same manufacturer on different days contained similar levels of AA (for potato chips, 1,008 and $875 \mathrm{ng} / \mathrm{g}$; for corn snack, 535 and 387 $\mathrm{ng} / \mathrm{g}$; for pretzel, 50 and $48 \mathrm{ng} / \mathrm{g}$; for roasted tea, 567 and $538 \mathrm{ng} / \mathrm{g}$ ).

The variety of AA content in foods might result from the differences in raw materials and processing conditions such as temperature and heating time. It was reported that the Maillard reaction is involved in the formation of AA; the key precursors are asparagine and glucose, and water enhanced the reaction ${ }^{9), 10)}$. The foods containing much water tended to have low levels of AA compared with the dry foods (Fig. 3). The water content might be one of the factors affecting the formation and/or decomposition of AA in foods. The foods fried or roasted at high temperature tended to have higher levels of AA than the foods boiled in water. The potato products tended to contain high levels of AA compared with similar products made from wheat or corn.

\section{Conclusion}

1) An LC/MS method for the analysis of AA in foods was developed. The method consisted of extraction with a mixture of water and acetone, clean-up by washing with dichloromethane and on C18, ACCUCAT and PSA cartridge-columns, and then LC/MS (SIR) using column switching.

2) The mean recoveries of AA from potato chips, corn snack, pretzel and roasted tea spiked at the level of $500 \mathrm{ng} / \mathrm{g}$ were $99-101 \%$ and the SD were $0.3-1.6 \%$, when corrected based on internal standard AA-1- ${ }^{13} \mathrm{C}$. 
The LOD of AA in foods was $9 \mathrm{ng} / \mathrm{g}$.

3) AA contents of various foods were analyzed by the developed method. AA was found in potato chips and French-fried potatoes at the levels of 467-3,544 ng/ $\mathrm{g}$, and in other foods except for one sample of "karinto" at the level of $<\mathrm{LOD}-567 \mathrm{ng} / \mathrm{g}$.

\section{References}

1) Rosén, J., Hellenäs, K.-E., Analysis of acrylamide in cooked foods by liquid chromatography tandem mass spectrometry. Analyst, 127, 880-882 (2002).

2) Tareke, E., Rydberg, P., Karlsson, P, Eriksson, S., Törnqvist, M., Analysis of acrylamide, a carcinogen formed in heated foodstuffs. J. Agric. Food Chem., 50, 4998-5006 (2002).

3) Bologna, L. S., Andrawes, F. F., Barvenik, F. W., Lentz, R. D., Sojka, R. E., Analysis of residual acrylamide in field crops. J. Chromatogr. Sci., 37, 240-244 (1999).

4) Castle, L., Campos, M.-J., Gilbert, J., Determination of acrylamide monomer in hydroponically grown tomato fruits by capillary gas chromatography-mass spectro- metry. J. Sci. Food Agric., 54, 549-556 (1991).

5) Castle, L., Determination of acrylamide monomer in mushrooms grown on polyacrylamide gel. J. Agric. Food Chem., 41, 1,261-1,263 (1993).

6) Tareke, E., Rydberg, P., Karlsson, P., Eriksson, S., Törnqvist, M., Acrylamide: a cooking carcinogen? Chem. Res. Toxicol., 13, 517-522 (2000).

7) Cutié, S. S., Kallos, G. J., Determination of acrylamide in sugar by thermospray liquid chromatography/mass spectrometry. Anal. Chem., 58, 2425-2428 (1986).

8) Nemoto, S., Takatsuki, S., Sasaki, K., Maitani, T., Determination of acrylamide in foods by $\mathrm{GC} / \mathrm{MS}$ using ${ }^{13} \mathrm{C}$ labeled acrylamide as an internal standard. J. Food Hyg. Soc. Japan, 43, 371-376 (2002).

9) Mottram, D. S., Wedzicha, B. L., Dodson, A. T., Acrylamide is formed in the Maillard reaction, Nature, 419 , 448-449 (2002)

10) Stadler, R. H., Blank, I., Varga, N., Robert, F., Hau, J., Guy, P. A., Robert, M. C., Riediker, S., Acrylamide from Maillard reaction products. Nature, 419, 449-450 (2002). 